\title{
The Efficacy of Dienogest for the Treatment of Endometriosis and Its Pharmaco-Economic Assessment in the Caucasian Region
}

Andguladze Mariami MD. Tevdorashvili George MD.PhD. Tevdorashvili David MD. PhD. Tevdorashvili Mariam MD. 跑

Tbilisi State Medical University, Department of Obstetrics and Gynecology, Tbilisi, Georgia

P. Shotadze Tbilisi Medical Academy, Department of Obstetrics and Gynecology, Tbilisi, Georgia

Medical Center "LASER", Department of Obstetrics and Gynecology, Tbilisi, Georgia

\section{Introduction :}

Endometriosis remains a highly prevalent and long-lasting condition in women of reproductive age

- The exact prevalence of endometriosis is unknown but estimates range from 2 to $10 \%$ within the general female population, but up to $50 \%$ in infertile women[2].

Prevalence of endometriosis might vary with ethnicity and it is one of the most common problem for the Caucasian region.

- Dienogest is an oral progestin that is approved in many countries for the treatment of endometriosis in women of reproductive age[6].

DNG provides a focused therapeutic effect on endometrial tissue, with no relevant androgenic, mineralocorticoid or glucocorticoid activity[6] .

\section{Objective :}

According to the official data, based on the birth rate in the Caucasian region and its low social-economic status, we decided to study

- The therapeutic efficacy and safety of Dienogest

- To assess its pharmaco-

economic effect in our region.

\section{Methods :}

- Open, single-center, randomized trial

- Patients are administered DNG orally at a daily dose $2 \mathrm{mg}$ (n-34) or $4 \mathrm{mg}(\mathrm{n}-38)$ for a maximum period of 6 months

- A total of 72 patients ( $30 \pm 6$ years of age) with histologically confirmed endometriosis at stages I, II or III according to the rAFS score - were randomized to receive study medication[3] - Participants had good general health

- Tablets of Dienogest were taken orally, regardless of food intake, a1 the same time every day
There were no notable differences between the treatment groups in mean age to menarche, parity, mean number of abortions, infertility or menstrual history or prior use of medication

Women were required to use a nonhormonal barrier contraceptive method throughout the study

Patients were randomised to one of two treatment groups via random selection

34 patients were included in the $2 \mathrm{mg}$ group and 38 -in the $4 \mathrm{mg}$. group

Each patient received 24 weeks of treatment after a screening visit and a baseline observation period covering one menstrual cycle

Endometriosis symptoms were recorded at baseline and after 4,16 and 24 weeks of treatment[1]

The effect of DNG on endometriotic lesions was assessed by transvaginal ultrasound (GE Voluson Expert)

The final assessment of the effect was done via endoscopy (Karl Storz endoscope) after the end of the treatment

- Adverse events were documented throughout the study.

\section{Results :}

After 24weeks of treatment, the rates for dysmenorrhea were reduced from $73 \%$ to $14 \%$ in the $2 \mathrm{mg}$ group and $12 \%$ in the $4 \mathrm{mg}$ group $(\mathrm{P}<0,001)$.

Figure1-A

\section{Pre-menstrual pain was} reported by $4 \%$ of patients out of $51 \%$ in both treatment groups $(\mathrm{P}<0,001)$ (Figure 1-B), whereas

The degree of dyspareunia was reduced from $63 \%$ to $9 \%$ in the $2 \mathrm{mg}$ group and $7 \%$ in the $4 \mathrm{mg}$ group $(\mathrm{P}<0,001)$ according to VAS. Figure1-C
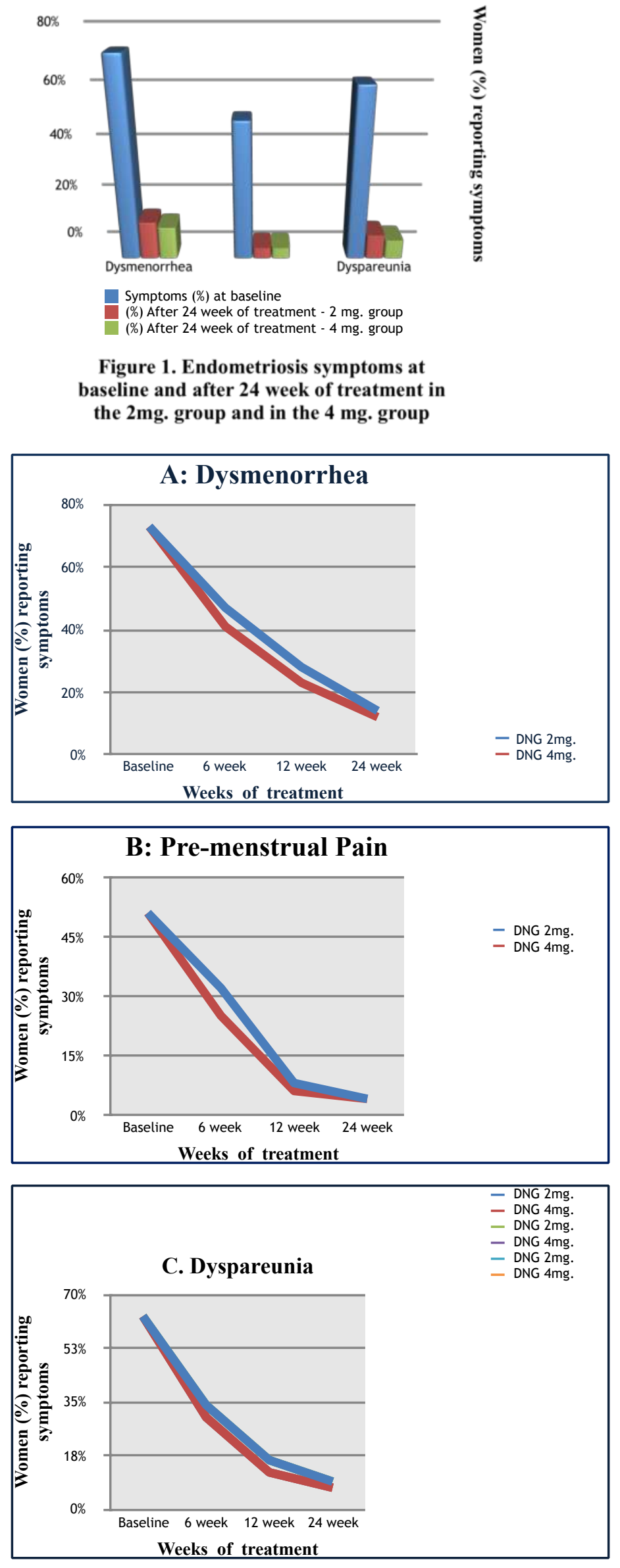

The most common adverse events were:

- Mood swings $-12 \%$ in the $2 \mathrm{mg}$ group and $14,2 \%$ in the $4 \mathrm{mg}$ group $(\mathrm{P}<0,001)$;

Headache $-7,1 \%$ in the $2 \mathrm{mg}$ group and $9,7 \%$ in the $4 \mathrm{mg}$ group $(\mathrm{P}<0,001)$;

Acne - 7\% in the $2 \mathrm{mg}$ group and $9,4 \%$ in the $4 \mathrm{mg}$ group $(\mathrm{P}<0,001)$;

Nausea $-5 \%$ in the $2 \mathrm{mg}$. group and 7,2\% in the $4 \mathrm{mg}$ group $(\mathrm{P}<0,001)$. (Figure 2.)

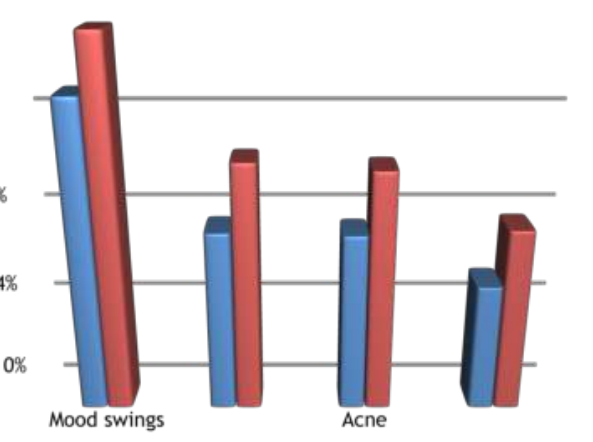

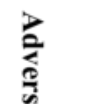

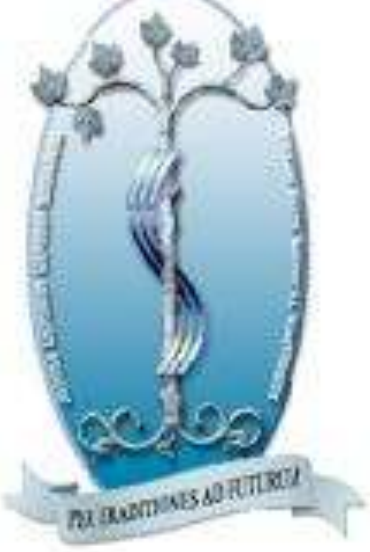

\section{Conclusions :}

In Caucasian women the $2 \mathrm{mg} /$ day dose of DNG has almost the same effect as the $4 \mathrm{mg}$ dose[4-6]. Moreover, its more safe and comfortable for patients with less severe adverse affects and thus has a clear economic advantage (DNG 2mg. N28 costs-58,2€ according to the Georgian National Bank's official exchange rate). Correct treatment based on the principle - balanced clinical and economic results is observed in case of treatment with Dienogest $2 \mathrm{mg}$. which is profitable for patients, clinics and also insurance companies.

\section{References:}

Brown J, Kives S and Akhtar M. Progestagens and antiCochrane Cochrane Database Syst Rev 2012; 3:CD002122. . Meuleman C, Vandenabeele B, Fieuws S, Spiessens C, Tometriosis in infertile woogen with normal ovulation an normospermic partners. Fertil Steril 2009; 92:68-74 3. Kohler G, Faustmann TA, Gerlinger C, Seitz C, Mueck $\mathrm{AO}$. A dose-ranging study to determine the efficacy and
safety of 1,2 and $4 \mathrm{mg}$ of dienogest daily for endometriosis. Int J Gynaecol Obstet 2010;108:21-25. 4. Petraglia, $F$, et al, Reduced pelvic pain in women with endometriosis: efficacy of long-term dienogest treatment. Arch Gynecol Obstet 2012, 285(1):167-73. 5. Schrager S, Falleroni J, Edgoose J. Evaluation and treatment of endometriosis. Am Fam Physician. 2013;87(2): 6. Prescribing Information - Dienogest (Visanne) Jul 201

Acknowledgements:

We want to thank theTbilisi State Medical University

Medical Center "LASER" for research opportunity. Thanks to all the staff of the clinic for help and support during the whole period of study.

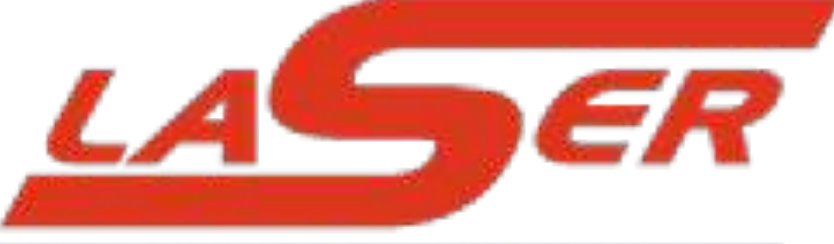

MEDICAL CENTER

Contact Information:

Tbilisi State Medical University

33 Vazha-Pshavela Ave.

0186, Tbilisi,Georgia

Phone : (+995 32) 2542439

E-mail: pr@tsmu.edu.ge

LLC. Medical Center "LASER"

18 Baktrioni str. 0194,Tbilisi, Georgia

Phone/Fax: (+995 32) 2361418

E-mail: info@laser.ge

P.Shotadze Tbilisi Medical Academy

Khetevan Tsamebuli Ave 51/2 